\title{
An Innovative Online Qualitative Study to Explore the Symptom Experience of Patients with Primary Sjögren's Syndrome
}

\author{
Kerry Gairy (D) · Keith Ruark · Susan M. Sinclair · Helen Brandwood • \\ Linda Nelsen
}

Received: May 22, 2020 / Published online: July 28, 2020

(C) The Author(s) 2020

\begin{abstract}
Introduction: Primary Sjögren's syndrome (pSS) is a complex, heterogenous autoimmune disease; no immunomodulatory drug has demonstrated efficacy, and no current treatments target the underlying cause. This study aimed to explore the disease and treatment experiences of patients with pSS.
\end{abstract}

Digital Features: To view digital features for this article go to: https://doi.org/10.6084/m9.figshare.12608414.

Electronic Supplementary Material The online version of this article (https://doi.org/10.1007/s40744020-00220-9) contains supplementary material, which is available to authorized users.

K. Gairy $(\bowtie)$

Value Evidence and Outcomes, GSK, Brentford,

Middlesex, UK

e-mail: kerry.x.gairy@gsk.com

K. Ruark · S. M. Sinclair

Syneos Health, Morrisville, NC, USA

S. M. Sinclair

University of North Carolina Wilmington,

Wilmington, NC, USA

H. Brandwood

HealthUnlocked, London, UK

L. Nelsen

Value Evidence and Outcomes, Patient Centered Outcomes, GSK, Upper Providence, Collegeville, PA, USA
Methods: This qualitative study (208399) comprised moderated online forum discussions and online one-to-one questions conducted in the USA over a 2-week period. Participants were selfreported patients with pSS; physician confirmation of diagnosis was sought. Participants described disease and symptom severity and satisfaction with current pSS treatments. Qualitative data analysis was performed using inductive coding analysis via open coding.

Results: Fifty-two participants entered the study, of whom 48 provided analysable data. Symptoms were described as highly unpredictable and variable, with fatigue rated as the most severe and burdensome. Participants discussed how their pSS symptoms and the frequent need for regular treatment impacted their daily activities, social life, career and finances. Many participants perceived a poor understanding of pSS amongst physicians, leading to emotional distress and difficulties obtaining a diagnosis. All participants stated that an ideal medication would address the cause of pSS and not just treat symptoms.

Conclusion: New insights into patients' perspectives of pSS were generated from online discussion forums, revealing the additional impact of unpredictable symptoms and multiple symptomatic treatments to the high disease burden. Improving physician education of pSS may help to alleviate frustrations and delays associated with diagnosis; the advent of novel effective treatments would be welcomed by patients with pSS. 
Keywords: Fatigue; Patient experience; Primary Sjögren's syndrome

\section{Key Summary Points}

\section{Why carry out this study?}

There is a lack information on the experience of primary Sjögren's syndrome (pSS) directly from the patient's perspective. The aim of this study was to explore the disease and treatment experiences of patients with pSS.

\section{What was learned from the study?}

This qualitative study demonstrated that the cardinal symptoms of pSS are unpredictable and vary considerably from day to day. This unpredictability, as well as the need for constant attention to manage multiple symptoms, has a negative impact on all aspects of patients' lives.

Many patients felt that physicians lacked understanding of pSS, contributing to their frustration and emotional distress.

Fatigue was the symptom for which patients most desired a more effective treatment. The availability of additional treatment options could improve patient-physician dialogue and reduce emotional distress.

\section{INTRODUCTION}

Primary Sjögren's syndrome (pSS) is a complex autoimmune disease characterised by secretory gland dysfunction. Patients with pSS typically experience dryness of the mouth, eyes and other mucous membranes, fatigue and joint pain. This heterogenous disease is complex and can range from isolated glandular involvement to widespread extra-glandular manifestations across multiple organs and systems, with emphasis on vasculitis, peripheral neuropathy and interstitial lung disease [1, 2]. These systemic, extra-glandular complications occur in $20-40 \%$ of patients [3], and the disease is associated with a significantly increased risk of B-cell non-Hodgkin's lymphoma [4], with the relative risk as high as 15-20 compared with the general population $[5,6]$. These varied manifestations make pSS difficult to distinguish from related diseases; thus, diagnosis can be challenging. The estimated prevalence of pSS varies from $0.09 \%$ to $2.7 \%$ [7], and the female-to-male incidence ratio is 9:1 [8]. Patients with pSS have a significantly lower health-related quality of life (HRQoL) than patients without pSS and have increased levels of healthcare resource utilisation $[9,10]$.

Optimal treatment pathways are currently not well defined, and to date, no immunomodulatory drug has proven efficacy for pSS [3]. Although a combination of leflunomide and hydroxychloroquine has demonstrated efficacy at reducing disease activity and symptoms in a small-scale pilot trial [11], there are currently no approved disease-modifying drugs, reflecting an unmet need for effective treatments. Many current treatments are over the counter and target symptoms rather than their underlying causes. In addition, there is a lack of therapies that target both glandular and extra-glandular manifestations [12].

While the symptoms and impacts of pSS are characterised from a clinician's perspective, understanding a patient's experience of disease, including their symptoms, impacts of those symptoms on their ability to function and a patient's experience of HRQoL, can only be established with direct input from patients from the relevant population. Both the US Food and Drug Administration (FDA) and the European Medicines Agency note the importance of evaluating patient-reported outcomes (PROs) based on a patient's perception of their disease [13-15]. The FDA states that patients are true experts in their disease: "It's clear you have to start with an understanding of the impact of the disease on the people who have it. Also, what they would value most in terms of alleviation before you set up a measurement as we go into the future to be truly patient-focused" [16]. Therefore, while the clinician's characterisation of the key symptoms of pSS is well documented, 
there remains limited information on the experience of symptoms and impacts of pSS from a patient's perspective. A focus groupbased qualitative study in Austria investigated the symptoms and impacts of greatest importance to females with pSS and reported that pSS significantly impacts physical, psychological and social aspects of patient's lives [17]. However, this study sampled patients from one region in Austria and there is therefore a need to examine patients representing a broader demographic profile and clinical experiences within the wider population.

Widespread internet access has allowed qualitative research to be conducted online. Compared with traditional in-person interviews and focus groups, online approaches have several advantages, including facilitation of recruitment, greater ease of access for patients with disabilities, greater convenience for participants, fewer logistical complexities and reduced travel costs and time [18, 19]. Additionally, patients may be more willing to discuss sensitive issues online, leading to higher personal disclosure [17-19]. Thus, qualitative data collected with online methods is a promising alternative to face-to-face interviews [18].

Accordingly, this qualitative study used online forums and online one-to-one questions to explore pSS symptoms, impacts, and treatment experience.

\section{METHODS}

The primary objectives of this study were: (1) to understand the type, duration, variability and severity of symptoms and disease impacts upon functioning and HRQoL; (2) to understand treatment experiences and impacts amongst patients with pSS. Secondary objectives included to identify unmet needs from the patient perspective.

\section{Study Design}

This non-interventional, cross-sectional qualitative study (GSK study 208399) comprised semistructured, moderated online forums, online one-to-one questions and completion of PROs, conducted over a 2-week period for two cohorts (Cohort I: April 23-May 4, 2018; Cohort II: May 14-25, 2018). No formal endpoints were set, with the study designed to explore key topics and themes (Fig. 1). The online forum discussions were designed to help generate broad overviews of the issues related to pSS disease and treatment experienced by patients; participants could expand on topics introduced by others. Subsequent one-to-one online questions allowed these issues to be explored further. The focus groups, one-to-one questioning and polls were conducted through the HealthUnlocked website (https://healthunlocked.com). HealthUnlocked is the world's largest social network for health with $>1$ million registered users.

A discussion guide was developed based on pSS symptoms previously identified as bothersome to patients [20] and systemic manifestations and disease impacts associated with pSS $[17,21]$. Open questions were included to ensure that participant experiences not relating to cardinal pSS symptoms could be captured. Additionally, structured polls were conducted alongside the one-to-one questions.

On days 1, 8 and 12, participants completed the Patient Global Assessment of disease activity (PtGA) by rating the current severity of their pSS overall using a numeric rating scale (NRS) of $0-10$ $(0=$ none/absent; $10=$ worst imaginable $)$. On day 3, participants were asked to discuss and rate the current severity of their dry eye, dry mouth, fatigue and pain symptoms from 0 to 10 individually on an NRS. On day 10, participants rated their satisfaction with current pSS treatments on an NRS of $1-10 \quad(1=$ not satisfied at all; $10=$ completely satisfied). Following the qualitative research period (day 12), participants were invited to complete the Profile of Fatigue and Discomfort-Sicca Symptom Inventory-Short Form (PROFAD-SSI-SF) questionnaire [22] and the Functional Assessment of Chronic Illness Therapy Fatigue Scale (FACIT-fatigue), version 4.0 [23].

\section{Ethical Considerations}

All participants provided informed consent for their participation and completed a medical information release authorisation form. The 


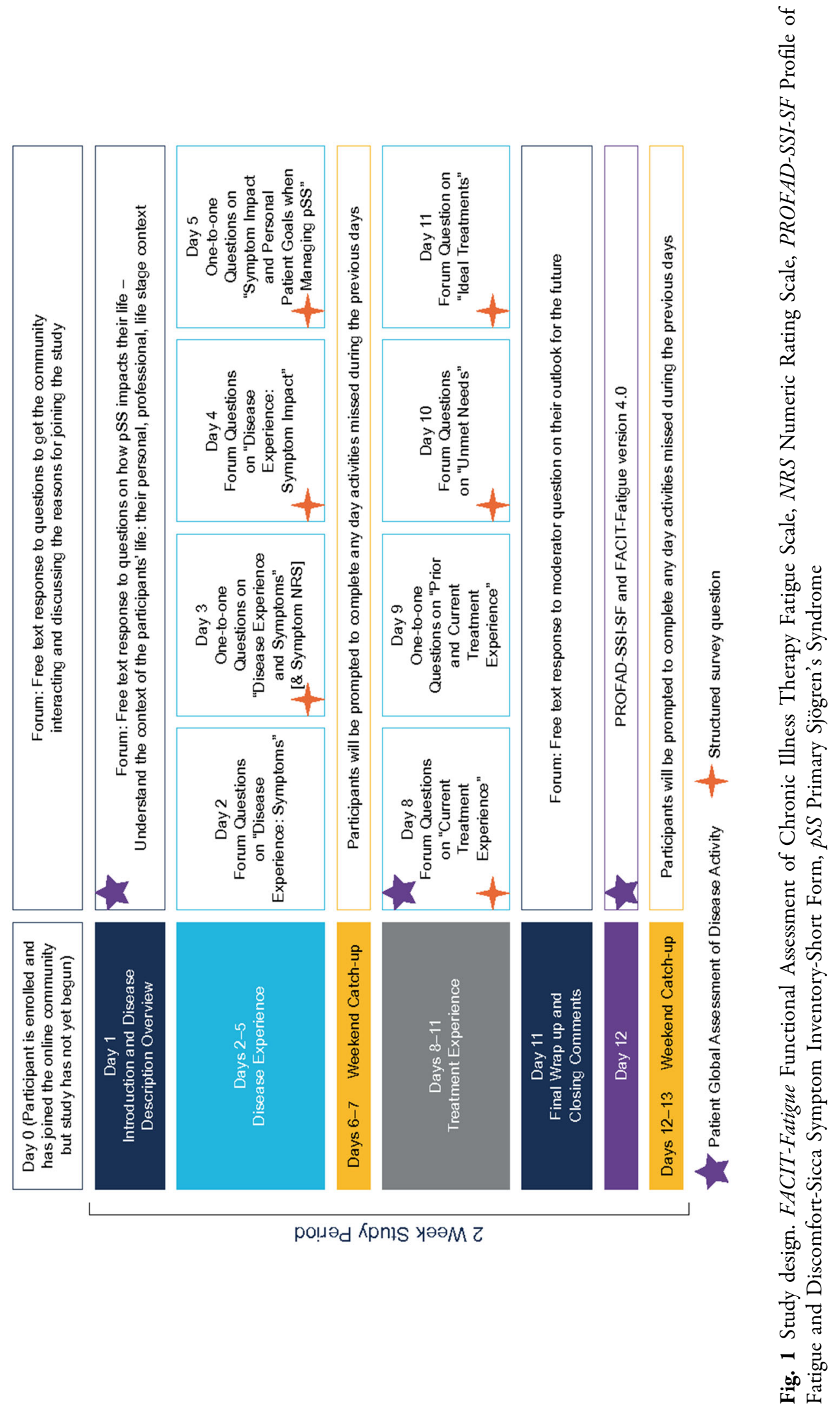


study protocol was reviewed and approved by the New England Independent Review Board and was conducted in accordance with the Declaration of Helsinki. Participants were financially compensated for participation if they answered $75 \%$ of questions and actively participated.

\section{Patient Involvement}

Two cohorts were included to enable meaningful interaction amongst a smaller number of participants within the online forum, whilst providing the opportunity to revise the discussion guide between the cohorts if necessary. Up to 60 adult patients (20-30 per cohort) with pSS in the USA were targeted through the HealthUnlocked website. Participants responded to an online advertisement on the HealthUnlocked website and completed a digital screener. Participants underwent a phone assessment by a research nurse before being invited to take part in the study. Confirmation of diagnosis was sought for all enrolled participants from their treating physician.

Inclusion criteria were: male or female, $\geq 18$ years of age; diagnosed with pSS and current symptoms of oral and ocular dryness and fatigue; willing to comply with all study procedures and available for the study duration; based in the USA and able to communicate in written English. Participants were excluded if they were diagnosed with systemic lupus erythematosus, rheumatoid arthritis or systemic sclerosis in addition to Sjögren's syndrome.

\section{Data Analysis}

Qualitative data were subject to inductive coding analysis via open coding by SMS, where KG, $\mathrm{KR}$ and LN reviewed and advised on the coding structure [24]. All data analysis was conducted using MaxQDA (Berlin, Germany). Inductive content analysis was used to derive categories from the patient data; categories were grouped under higher order headings to identify the main categories and themes. Data saturation was monitored during coding to determine when saturation, the point at which the addition of new participants does not introduce new concepts or themes, was reached. For Cohort I, convenience sampling was used to recruit the required number of participants. For Cohort II, a combination of convenience and quota sampling was employed to support recruitment of a sample representative of the key demographic and clinical characteristics of pSS.

Descriptive statistics were derived for the PROFAD-SSI-SF and FACIT-Fatigue domain and total scores and summary statistics reported.

\section{RESULTS}

\section{Study Population}

An overview of participant recruitment is shown in Fig. 2. In total, 52 participants entered the study, of whom 48 (Cohort I $n=22$; Cohort II $n=26$ ) contributed to at least one discussion, thereby providing analysable data. Of these, 43 (89.6\%; Cohort I $n=22$; Cohort II $n=21$ ) responded to $\geq 75 \%$ of research topics. A physician-confirmed pSS diagnosis was obtained for 29 (60.4\%) participants. For seven participants, the physician was unable to confirm pSS. Symptoms reported at screening were similar for participants with a physician-confirmed and unconfirmed pSS diagnosis.

Baseline characteristics and demographics are shown in Table 1 . The mean (standard deviation [SD]) age of the study population was 55.3 (11.4) years (range: 20-73) and 45 (93.8\%) participants were female. Almost half of participants $(n=21 / 48 ; 43.8 \%)$ had been diagnosed with pSS for between 1 and 5 years and nearly all participants ( $n=47 / 48 ; 97.9 \%$ ) self-reported dry mouth, dry eyes, fatigue and joint pain/ stiffness as symptoms of pSS at screening.

\section{Symptoms}

\section{Symptoms Experienced}

Participants discussed a wide variety of symptoms throughout the forum discussions and one-to-one questioning (Table 2). Overall, $>20$ symptoms or conditions were reported by 


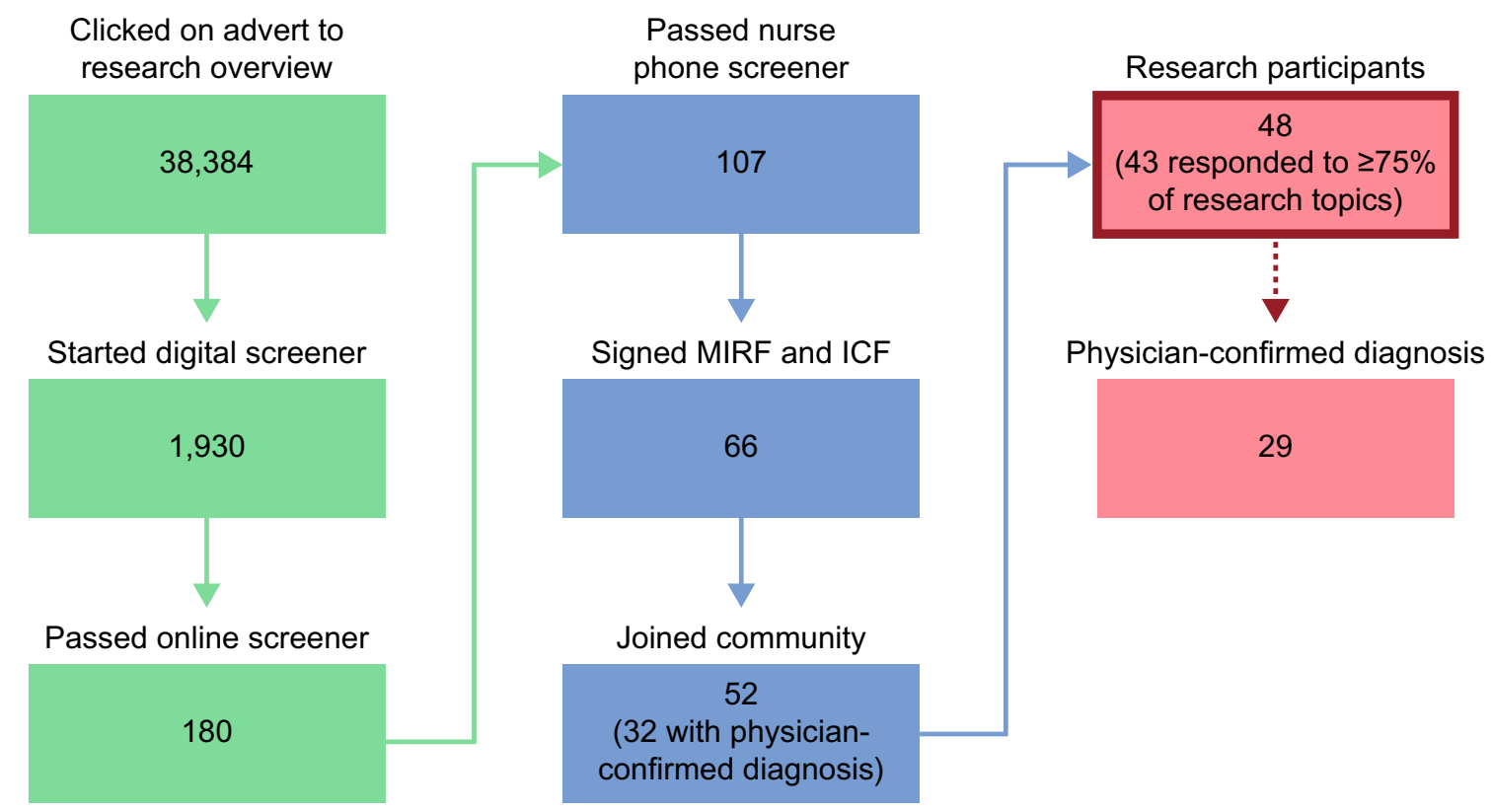

Fig. 2 Participant recruitment. ICF informed consent form, MIRF medical information release authorisation form

$>25 \%$ of the study population. Most participants $(n=37 / 48,77.1 \%)$ had $\geq 10$ symptoms or conditions. Symptoms were balanced between cohorts (Table 2).

On day 5, when questioned about experiencing specific symptoms in addition to dryness, pain and fatigue, participants reported experiencing severe glandular swelling $(n=13$ / $34,38.2 \%)$, pulmonary disease $(n=7 / 34$, $20.6 \%)$, anaemia $(n=5 / 34,14.7 \%)$, vasculitis $(n=5 / 34,14.7 \%)$, renal disease $(n=1 / 34,2.9 \%)$ and 'other' ( $n=25 / 34,73.5 \%)$ (Electronic Supplementary Material Table S1). 'Other' symptoms included Raynaud's phenomenon $(n=7 /$ $25,28.0 \%)$, concentration problems $(n=5 / 25$, $20.0 \%)$, irritable bowel syndrome $(n=4 / 25$, $16.0 \%)$, fibromyalgia $(n=3 / 25,12.0 \%$, all in Cohort I), asthma $(n=3 / 25,12.0 \%)$ and antiphospholipid syndrome $(n=2 / 25,8.0 \%)$.

\section{Symptom Severity}

On day 1, participants reported a mean (SD) PtGA symptom severity score of 5.82 (1.91), with the mean severity subsequently varying throughout the study period. During the study period, mean (SD) PtGA symptom severity scores ranged from 5.61 (1.83) to 6.13 (2.06). Mean (range) severity scores for the four most common pSS symptoms reported on day 3 were: fatigue 6.2 ([0-10), dry mouth 5.8 (2-9), dry eyes $5.3(1-8.5)$ and pain $5.0(0-9)$. Of the 27 participants who reported a severity score for fatigue, dry mouth, dry eyes and pain, 18 $(66.6 \%)$ reported a mean severity score $\geq 5$ for all these symptoms. A word cloud highlighting the most bothersome symptoms reported by participants is shown in the Electronic Supplementary Material Fig. S1. Mean (SD) PROFADSSI-SF and FACIT-Fatigue scores of the participants were $36.9(12.0 ; n=38)$ and 21.6 (11.9; $n=41)$, respectively.

Most participants $(n=29 / 40 ; 72.5 \%)$ reported daily fatigue, but several reported that the severity varied day-to-day $(n=10 / 40,25.0 \%)$, with increased fatigue reported with daily activities and severely increased fatigue following major activities, such as travel. Dry mouth was frequently reported to vary with hydration; more than half $(n=24 / 42 ; 57.1 \%)$ mentioned the need to prevent discomfort, choking or coughing by adding moisture to the mouth, such as by drinking water or using lozenges. Most participants also reported that they experienced a constant daily level of pain $(n=23 / 33$; $69.7 \%)$ and eight $(n=8 / 33 ; 24.2 \%)$ stated that their pain varies within a day, of whom five 
Table 1 Participant characteristics and demographics by cohort and physician-confirmed pSS diagnosis subgroups at screening

\begin{tabular}{|c|c|c|c|c|c|}
\hline & $\begin{array}{l}\text { Cohort I } \\
(n=22)\end{array}$ & $\begin{array}{l}\text { Cohort II } \\
(n=26)\end{array}$ & $\begin{array}{l}\text { Physician- } \\
\text { confirmed } \\
(n=29)\end{array}$ & $\begin{array}{l}\text { Physician- } \\
\text { unconfirmed } \\
(n=19)\end{array}$ & $\begin{array}{l}\text { Total } \\
(N=48)\end{array}$ \\
\hline \multicolumn{6}{|l|}{ Age, years, $n(\%)$} \\
\hline$<30$ & $0(0)$ & $1(3.8)$ & $1(3.4)$ & $0(0)$ & $1(2.1)$ \\
\hline $30-39$ & $2(9.1)$ & $1(3.8)$ & $2(6.9)$ & $1(5.3)$ & $3(6.3)$ \\
\hline $40-49$ & $5(22.7)$ & $4(15.4)$ & $5(17.2)$ & $4(21.1)$ & $9(18.8)$ \\
\hline $50-59$ & $3(13.6)$ & $10(38.5)$ & $7(24.1)$ & $6(31.6)$ & $13(27.1)$ \\
\hline $60-69$ & $9(40.9)$ & $8(30.8)$ & $10(34.5)$ & $7(36.8)$ & $17(35.4)$ \\
\hline $70-79$ & $3(13.6)$ & $1(3.8)$ & $4(13.8)$ & $0(0)$ & $4(8.3)$ \\
\hline \multicolumn{6}{|l|}{ Gender, $n(\%)$} \\
\hline Female & $20(90.9)$ & $25(96.2)$ & $27(93.1)$ & $18(94.7)$ & $45(93.8)$ \\
\hline \multicolumn{6}{|l|}{ Duration of pSS diagnosis, $n$ (\%) } \\
\hline$<1$ year & $3(13.6)$ & $4(15.4)$ & $2(6.9)$ & $5(26.3)$ & $7(14.6)$ \\
\hline $1-5$ years & $9(40.9)$ & $12(46.2)$ & $13(44.8)$ & $8(42.1)$ & $21(43.8)$ \\
\hline $5-10$ years & $5(22.7)$ & $6(23.1)$ & $8(27.6)$ & $3(15.8)$ & $11(22.9)$ \\
\hline$>10$ years & $5(22.7)$ & $4(15.4)$ & $6(20.7)$ & $3(15.8)$ & $9(18.8)$ \\
\hline \multicolumn{6}{|l|}{ Self-reported symptoms, $n$ (\%) } \\
\hline Dry mouth & $21(95.5)$ & $26(100)$ & $28(96.6)$ & $19(100)$ & $47(97.9)$ \\
\hline Dry eye & $22(100)$ & $25(96.2)$ & $28(96.6)$ & $19(100)$ & $47(97.9)$ \\
\hline Fatigue & $22(100)$ & $25(96.2)$ & $28(96.6)$ & $19(100)$ & $47(97.9)$ \\
\hline Joint pain/stiffness & $21(95.5)$ & $26(100)$ & $28(96.6)$ & $19(100)$ & $47(97.9)$ \\
\hline $\begin{array}{l}\text { Dry cough or shortness of breath either at rest } \\
\text { or after exertion }\end{array}$ & $20(90.9)$ & $23(88.5)$ & $25(86.2)$ & $18(94.7)$ & $43(89.6)$ \\
\hline Muscle weakness around legs and core section & $20(90.9)$ & $20(76.9)$ & $24(82.8)$ & $16(84.2)$ & $40(83.3)$ \\
\hline $\begin{array}{l}\text { Swelling, tenderness, or pain in neck, around } \\
\text { collar bone, armpit, groin }\end{array}$ & $17(77.3)$ & $15(57.7)$ & $20(69.0)$ & $12(63.2)$ & $32(66.7)$ \\
\hline $\begin{array}{l}\text { Red or purple swelling on skin that looks like } \\
\text { burst blood vessels }\end{array}$ & $15(68.2)$ & $15(57.7)$ & $19(65.5)$ & $11(57.9)$ & $30(62.5)$ \\
\hline $\begin{array}{l}\text { Told by physician that other body functions } \\
\text { ever or currently affected }\end{array}$ & $14(63.6)$ & $22(84.6)$ & $22(75.9)$ & $14(73.7)^{\mathrm{a}}$ & $36(75.0)$ \\
\hline $\begin{array}{l}\text { Prescribed tablets, injections, or infusions to } \\
\text { treat problems caused by pSS in last } \\
12 \text { months }\end{array}$ & $17(77.3)$ & $20(76.9)$ & $23(79.3)$ & $14(73.7)$ & $37(77.1)$ \\
\hline
\end{tabular}

$p S S$ primary Sjogren's syndrome

a One participant reported "not sure" (Cohort II, not physician-confirmed) for "Told by physician that other body functions ever or currently affected'; all other participants reported either Yes or No 
Table 2 Frequency of symptoms and conditions reported by participants during discussion forums and one-to-one questioning

\begin{tabular}{|c|c|c|c|}
\hline Symptom/condition, $n$ (\%) & All participants $(N=48)$ & Cohort I $(n=22)$ & Cohort II $(n=26$ \\
\hline Dry eye & $47(97.9)$ & $22(100.0)$ & $25(96.2)$ \\
\hline Dry mouth & $47(97.9)$ & $21(95.5)$ & $26(100.0)$ \\
\hline Fatigue & $48(100.0)$ & $22(100.0)$ & $26(100.0)$ \\
\hline Pain & $42(87.5)$ & $21(95.5)$ & $21(80.8)$ \\
\hline Joint pain, stiffness, swelling & $37(77.1)$ & $16(72.7)$ & $21(80.8)$ \\
\hline Brain fog, issues with memory, concentration & $31(64.6)$ & $15(68.2)$ & $16(61.5)$ \\
\hline Muscle pain, weakness & $28(58.3)$ & $14(63.6)$ & $14(53.8)$ \\
\hline Anxiety & $28(58.3)$ & $12(54.5)$ & $16(61.5)$ \\
\hline Depression & $28(58.3)$ & $13(59.1)$ & $15(57.7)$ \\
\hline Gastrointestinal-related symptoms & $22(45.8)$ & $11(50.0)$ & $11(42.3)$ \\
\hline Dental issues & $27(56.3)$ & $11(50.0)$ & $16(61.5)$ \\
\hline Swollen glands/lymph nodes & $22(45.8)$ & $12(54.5)$ & $10(38.5)$ \\
\hline Cough & $17(35.4)$ & $6(27.3)$ & $11(42.3)$ \\
\hline Vertigo, dizziness, balance problems & $16(33.3)$ & $9(40.9)$ & $7(26.9)$ \\
\hline Headache, including migraine & $16(33.3)$ & $9(40.9)$ & $7(26.9)$ \\
\hline Neuropathy & $16(33.3)$ & $7(31.8)$ & $9(34.6)$ \\
\hline Pulmonary issues & $14(29.2)$ & $8(36.4)$ & $6(23.1)$ \\
\hline Dry skin & $14(29.2)$ & $7(31.8)$ & $7(26.9)$ \\
\hline Vaginal dryness & $14(29.2)$ & $12(54.5)$ & $2(7.7)$ \\
\hline Vision problems & $13(27.1)$ & $7(31.8)$ & $6(23.1)$ \\
\hline Dry nose & $13(27.1)$ & $8(36.4)$ & $5(19.2)$ \\
\hline Shortness of breath & $16(33.3)$ & $4(18.2)$ & $12(46.2)$ \\
\hline Sinus problems & $12(25.0)$ & $5(22.7)$ & $7(26.9)$ \\
\hline Sleeping difficulties & $11(22.9)$ & $3(13.6)$ & $8(30.8)$ \\
\hline Ear issues & $7(14.6)$ & $2(9.1)$ & $5(19.2)$ \\
\hline Hair loss & $10(20.8)$ & $4(18.2)$ & $6(23.1)$ \\
\hline Back/spine pain & $9(18.8)$ & $6(27.3)$ & $3(11.5)$ \\
\hline Urinary issues, including cystitis & $9(18.8)$ & $7(31.8)$ & $2(7.7)$ \\
\hline Constipation & $7(14.6)$ & $2(9.1)$ & $5(19.2)$ \\
\hline Photosensitivity & $7(14.6)$ & $6(27.3)$ & $1(3.8)$ \\
\hline Renal issues & $4(8.3)$ & $4(18.2)$ & $0(0.0)$ \\
\hline Reduced sense of taste & $4(8.3)$ & $1(4.5)$ & $3(11.5)$ \\
\hline
\end{tabular}


Table 2 continued

\begin{tabular}{llll}
\hline Symptom/condition, $\boldsymbol{n}(\%)$ & All participants $(\boldsymbol{N}=\mathbf{4 8})$ & Cohort I $(\boldsymbol{n}=\mathbf{2 2})$ & Cohort II $(\boldsymbol{n}=\mathbf{2 6})$ \\
\hline Vasculitis & $4(8.3)$ & $1(4.5)$ & $3(11.5)$ \\
Sensitive to sounds, noise & $4(8.3)$ & $3(13.6)$ & $1(3.8)$ \\
Anaemia & $3(6.3)$ & $1(4.5)$ & $2(7.7)$ \\
Facial pain & $3(6.3)$ & $0(0.0)$ & $3(11.5)$ \\
Costochondritis & $2(4.2)$ & $1(4.5)$ & $1(3.8)$ \\
Reduced sense of smell & $1(2.1)$ & $0(0.0)$ & $1(3.8)$ \\
No tears/cannot cry & $1(2.1)$ & $0(0.0)$ & $1(3.8)$ \\
Unintentional weight loss & $1(2.1)$ & $0(0.0)$ & $1(3.8)$ \\
\hline
\end{tabular}

reported that their pain worsens throughout the day.

Participants reported several negative triggers for pSS symptoms, most commonly stress $(n=17 / 35 ; 48.6 \%)$, physical overexertion $(n=14 / 35 ; 40.0 \%)$, changes in weather or temperature $(n=9 / 35 ; 25.7 \%)$ and issues with sleep $(n=6 / 35 ; 17.1 \%)$. Seven participants mentioned positive triggers that reduce symptom frequency, including keeping hydrated, rest and a low-stress lifestyle.

\section{Symptom Impacts}

In a poll question, $>80 \%(n=31 / 37)$ of participants indicated that their pSS symptoms impacted their personal daily routine and daily activities. A selection of quotes relating to the impacts of pSS symptoms are shown in Table 3.

\section{Impact on Social Functioning}

Of the 41 participants reporting impacts on social functioning from their pSS symptoms, 31 (75.6\%) indicated impacts on relationships with family and friends and 17 (41.5\%) reported impacts on recreational activities and hobbies. Nine $(22.0 \%)$ participants discussed having to cancel plans due to their pSS symptoms.

\section{Impact on Career and Ability to Work}

Of the 31 participants that discussed the impacts of pSS on their career, 15 (48.4\%) indicated they underperform at work due to
pSS, 7 (22.6\%) had to retire early, 5 (16.1\%) had to reduce their hours or move to part time, 4 $(12.9 \%)$ received disability benefit, 2 (6.5\%) stated they could not work, 2 (6.5\%) discussed losing career opportunities and 2 (6.5\%) mentioned that they use most of their sick and vacation leave for physician visits and illnesses. Nineteen $(61.3 \%)$ participants reported that pSS symptoms impacted their ability to work efficiently. Eight $(25.8 \%)$ indicated impacts from symptom management at work, such as needing rest periods.

\section{Impact on Finances}

Most participants $(n=34 / 44 ; 77.3 \%)$ reported concerns about the cost of managing pSS, although $10(22.7 \%)$ indicated that they currently found the costs of treatment manageable.

\section{Patient Experiences with pSS Management}

A key theme emerged indicating emotional distress and frustration related to pSS management, with participants frequently expressing frustration at the care they received (Table 3). Half of participants $(n=15 / 30 ; 50.0 \%)$ who contributed coded segments indicated dissatisfaction with current healthcare providers (HCPs), and only two ( $n=2 / 30 ; 6.7 \%)$ expressed satisfaction. Similarly, $15(50.0 \%)$ participants expressed a concern regarding the lack of knowledge about pSS by HCPs and 12 (40.0\%) reported that HCPs are frequently dismissive of 
Table 3 Example participant quotes from the forum

\begin{tabular}{|c|c|c|}
\hline Category & Aspect & Patient quote \\
\hline \multirow{5}{*}{$\begin{array}{l}\text { Symptom } \\
\text { descriptions }\end{array}$} & Dry eyes & "Dry eyes that feel like sand paper has been rubbed across them" \\
\hline & Dry mouth & $\begin{array}{l}\text { "I can't go anywhere without water or I will panic; none of the OTC products } \\
\text { work. The dryness wakes me up during the night and I can feel it all the way } \\
\text { down my throat and down into my chest. So, I imagine my lungs and other } \\
\text { organs are dried out too" }\end{array}$ \\
\hline & Fatigue & $\begin{array}{l}\text { "I feel weak with no energy reserves. I feel depleted before I even begin to do } \\
\text { something" }\end{array}$ \\
\hline & & $\begin{array}{l}\text { "I have trouble thinking and talking. I avoid answering the phone because I } \\
\text { don't even have the energy to talk" }\end{array}$ \\
\hline & Pain & $\begin{array}{l}\text { "I can, and often do, describe the Sjögren's pain as having the flu with all the } \\
\text { aches and pain throughout the body without the stomach and intestinal } \\
\text { issues. I have been at a } 4 \text { or } 5 \text { [out of } 10 \text { on a pain numeric response scale] } \\
\text { continually for } 25 \text { years" }\end{array}$ \\
\hline \multirow[t]{3}{*}{$\begin{array}{r}\text { Symptom } \\
\text { impacts }\end{array}$} & $\begin{array}{l}\text { Impact on social } \\
\text { functioning }\end{array}$ & $\begin{array}{l}\text { "Sometimes I have to cancel my plans because of being too tired. I have let } \\
\text { some relationships go because of the fatigue and cancelling plans, just don't } \\
\text { have the energy needed to keep up with a social life" } \\
\text { "I have given up golf because of the fatigue, muscle issues, joint pain, etc. For } \\
\text { home chores, I have to spread them out to preserve energy" }\end{array}$ \\
\hline & $\begin{array}{l}\text { Impact on career/ } \\
\text { ability to work }\end{array}$ & $\begin{array}{l}\text { "Last year I took all of my } 40 \mathrm{~h} \text { sick leave and my } 160 \mathrm{~h} \text { of vacation for } \\
\text { sickness and I was not even hospitalized. This was for physician } \\
\text { appointments and being home too tired and hurting to be at work" } \\
\text { "When I worked, I was an office manager for a local physician. But had to } \\
\text { leave that job } 3 \text { years ago as my symptoms got much worse. My Sjogren's has } \\
\text { greatly impacted my life, causing me to stop working and take an early } \\
\text { retirement" }\end{array}$ \\
\hline & Impact on finances & $\begin{array}{l}\text { “My finances have been affected tremendously. Copayment, coinsurance, } \\
\text { deductibles, MRI's, CT's, ultrasounds, MEDICATIONS! And I have } \\
\text { decent insurance! Part time work is not enough, and we have exhausted our } \\
\text { savings.... In addition, I cannot work full time and need to hire a } \\
\text { housekeeper to do the heavy cleaning. My retirement and savings have been } \\
\text { depleted due to this illness and my future is uncertain. Each year seems to } \\
\text { bring a new diagnosis or side effect” }\end{array}$ \\
\hline \multirow[t]{2}{*}{$\begin{array}{l}\text { Symptom } \\
\text { variability }\end{array}$} & & $\begin{array}{l}\text { "Everything I do depends on how I feel at that moment. Things can change } \\
\text { within minutes or hours" }\end{array}$ \\
\hline & & $\begin{array}{l}\text { "My symptoms vary greatly from day to day. Some days it seems as if I am } \\
\text { totally healthy and then other days I feel } 30 \text { years older than I really am" }\end{array}$ \\
\hline
\end{tabular}


Table 3 continued

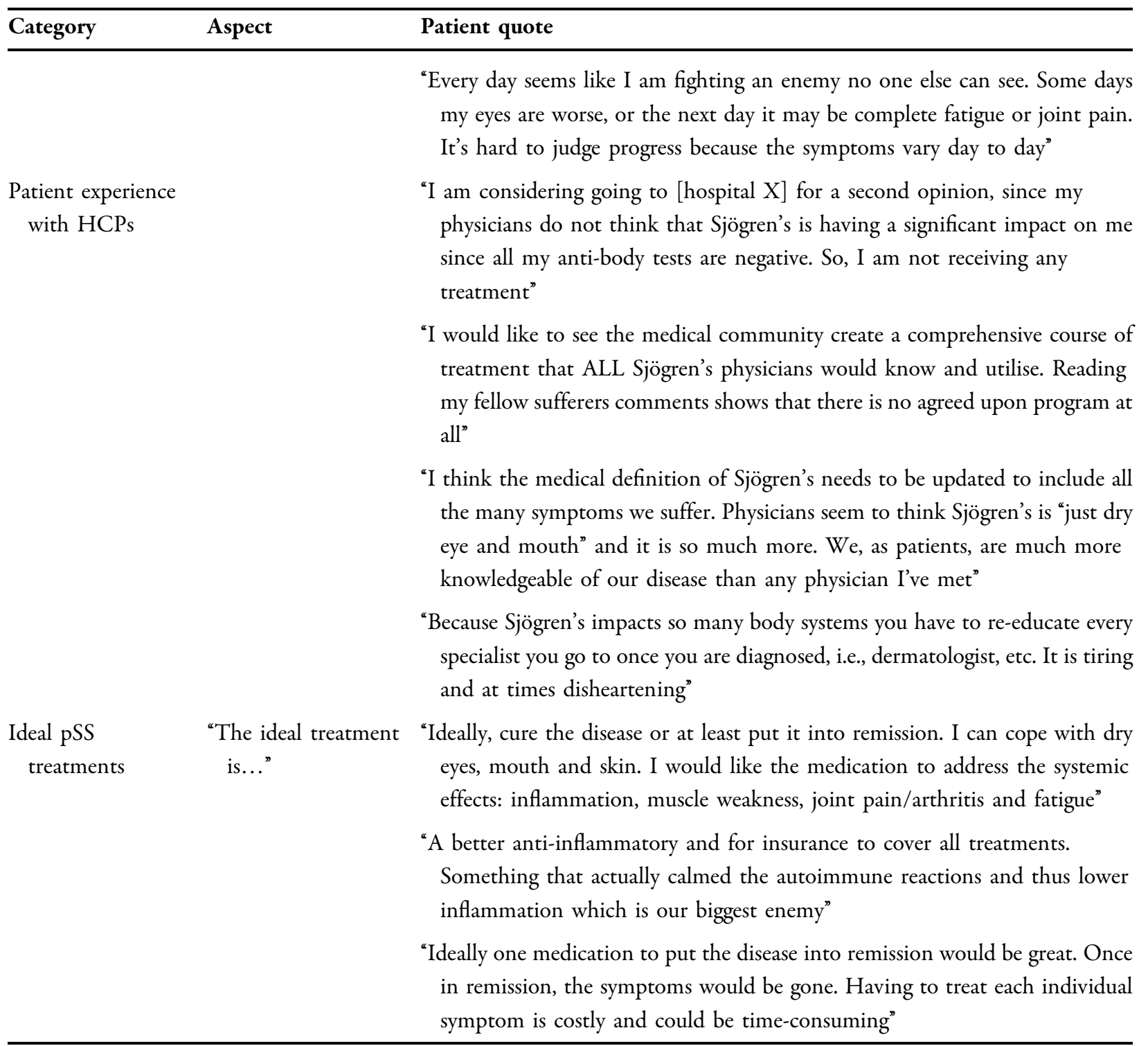

$C T$ computed tomography, HCP healthcare provider, MRI magnetic resonance imaging, OTC over the counter, $p S S$ primary Sjogren's syndrome

pSS symptoms and view the disease as "just dry eye and mouth". Eight (26.7\%) participants mentioned that they had to self-advocate and self-manage their symptoms before they were diagnosed and treated for pSS. A minority $(n=3 / 30 ; 10.0 \%)$ said that they had been misdiagnosed prior to their pSS diagnosis. Twentyfour $(70.6 \%)$ of the 34 participants who discussed concerns regarding the long-term impact of pSS were worried about disease progression.

At the time of the study, participants reported receiving a range of prescribed medications including hydroxychloroquine, gabapentin, cevimeline, duloxetine, prednisone, pilocarpine and adalimumab as well as topical cyclosporine A. Mean satisfaction with current treatment was 


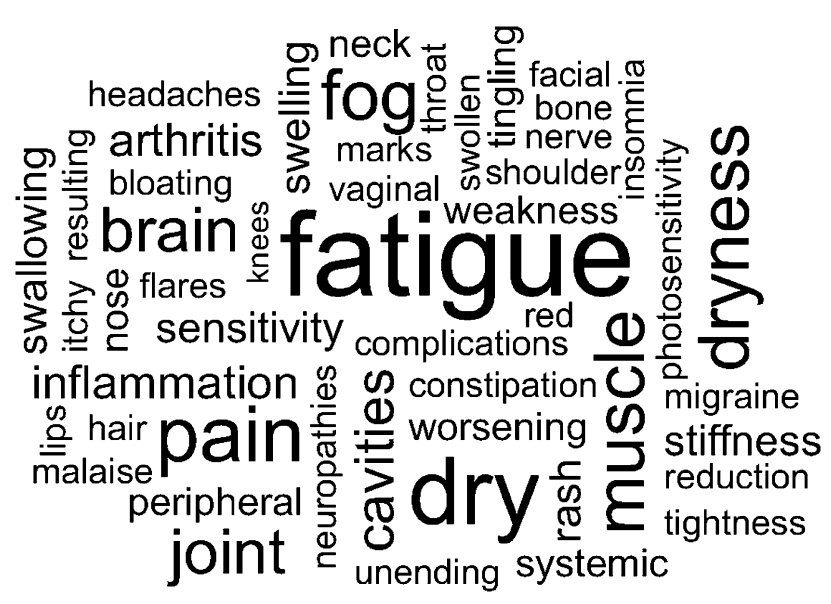

Fig. 3 Word cloud of symptoms that participants reported is unaddressed by currently available treatments. A larger font size denotes a more bothersome or unaddressed symptom than smaller fonts

5.39 (SD 2.02; range 1-8). A word cloud depiction of the pSS symptoms that participants reported to be unaddressed by current treatments is shown in Fig. 3. All participants viewed an ideal medication as something that would address the cause of pSS and not simply treat symptoms. A selection of quotes from participants regarding their ideal pSS treatments is given in Table 3.

\section{DISCUSSION}

This qualitative research study used online forums, online one-to-one patient questions, polls and PROs to explore pSS disease and treatment experience. Findings suggest an unmet pSS treatment need, whilst highlighting patientperceived inadequacies in the management of pSS by HCPs. One of the key emergent themes was that many patients experience difficulties obtaining a pSS diagnosis, often viewing their physicians as inadequately informed. Participants had low overall satisfaction with the efficacy of their treatments and the majority reported concerns over the cost of managing pSS, suggesting that new treatments should be effective as well as affordable. Similarly, the severity of many pSS symptoms was described as varying day to day, underlining the unpredictability of the disease and the need for patients to constantly address their symptoms.
Many aspects of patients' daily lives are impacted by their pSS symptoms, including home and social life, career and finances, as well as an associated emotional distress.

The results presented here are consistent with a previous in-person qualitative pSS study, which identified three categories of impacts related to pSS; physical, social/daily living and psychological/emotional [17]. As was found here, patients reported that core pSS symptoms impact their daily lives, leading to emotional impacts and worry over the future of their disease, such as financing treatment long term. Patients in this prior study also raised concerns regarding the lack of pSS awareness amongst physicians or an unwillingness to take symptoms seriously, extending the pre-diagnostic phase. Delays before diagnosis have also been reported in systemic lupus erythematosus [25], suggesting that improving the awareness of autoimmune diseases amongst HCPs could alleviate many patient concerns and frustrations.

The consistency of this innovative, online study with prior in-person studies supports this approach and suggests that online qualitative studies can be as informative as traditional faceto-face methods. As patient recruitment and enrolment were also carried out online, this allowed for all 48 patients to be recruited within a 46-day period. Therefore, an online-based study may be more efficient than in-person 
studies. Furthermore, patients may feel more comfortable discussing certain aspects of their disease than they would in person; for instance, there was an emphasis on vaginal dryness in the study population.

Fatigue was rated as the most severe symptom and the symptom that patients most wished they could change. This may be a consequence of treatments for other common symptoms, such as cyclosporine A for dry eye, being more effective than those for fatigue.

This study is not without limitations. As this was primarily a qualitative study, it is difficult to draw conclusions from these findings alone, although the observations presented here may inform future quantitative and focused studies. Additionally, only patients willing and able to respond to an online research study were included, which may not be representative of the overall patient population. A physicianconfirmed diagnosis of pSS could only be obtained for $60.4 \%$ of patients; non-responsive physicians were followed up but the window for a response was limited by the 2-week study duration. However, the physician-confirmed and physician-unconfirmed subgroups were similar in terms of key demographics and clinical characteristics, and provided similar characterisations of their experience of pSS, suggesting that data from both subgroups are informative. Missing data may have arisen based on patients' willingness or ability to participate fully each day, despite the 2-week period given for responses and multiple probes by a moderator. Males represented only $6 \%$ of the study population; however, it is estimated that Sjögren's syndrome is 9-14 times more prevalent in females than males [26]. Finally, disease information was provided by patients and not physicians, with no further opportunity to investigate the pSS diagnosis, for instance, in terms of specific extra-glandular manifestations.

\section{CONCLUSIONS}

This qualitative study indicates that the symptoms of pSS place a high burden on physical, emotional and social aspects of patient lives. Currently available treatments do not appear to adequately relieve the most common pSS symptoms, especially fatigue. Novel effective treatment types would be welcomed by patients with pSS.

\section{ACKNOWLEDGEMENTS}

The authors wish to thank the participants of this study for their time and contribution. The authors also wish to thank Carla Lema Tome for her contributions to the design of this study.

Funding. This study (208399) and the Rapid Service Fee were funded by GSK.

Medical Writing Assistance. Medical writing support was provided by Sam Halliwell, $\mathrm{PhD}$, and Liam Campbell, PhD, of Fishawack Indicia Ltd, UK, and was funded by GlaxoSmithKline (GSK).

Authorship. All named authors meet the International Committee of Medical Journal Editors (ICMJE) criteria for authorship for this article, take responsibility for the integrity of the work as a whole, and have given their approval for this version to be published.

Authorship Contributions. All authors contributed to the conception or design of the study and the analysis/interpretation of the data. Keith Ruark and Helen Brandwood also contributed to the acquisition of data. All authors take responsibility for the integrity of the work as a whole, and have given their approval for this version to be published.

Disclosures. Kerry Gairy and Linda Nelsen are employees of GSK and hold stocks and shares in the company. Keith Ruark is an employee with Syneos Health and Susan M. Sinclair is a consultant with the company; Helen Brandwood is an employee of HealthUnlocked and holds shares in the company.

Compliance with Ethics Guidelines. All participants provided informed consent for their participation and completed a medical information release authorisation form. The 
study protocol was reviewed and approved by the New England Independent Review Board and was conducted in accordance with the Declaration of Helsinki. Participants were financially compensated for participation if they answered $75 \%$ of questions and actively participated.

Data Availability. Information on GSK's data sharing commitments and requesting access to anonymised individual participant data and associated documents from GSKsponsored studies can be found at www. clinicalstudydatarequest.com.

Open Access. This article is licensed under a Creative Commons Attribution-NonCommercial 4.0 International License, which permits any non-commercial use, sharing, adaptation, distribution and reproduction in any medium or format, as long as you give appropriate credit to the original author(s) and the source, provide a link to the Creative Commons licence, and indicate if changes were made. The images or other third party material in this article are included in the article's Creative Commons licence, unless indicated otherwise in a credit line to the material. If material is not included in the article's Creative Commons licence and your intended use is not permitted by statutory regulation or exceeds the permitted use, you will need to obtain permission directly from the copyright holder. To view a copy of this licence, visit http://creativecommons.org/licenses/by$\mathrm{nc} / 4.0 /$.

\section{REFERENCES}

1. Hammitt KM, Naegeli AN, van den Broek RWM, Birt JA. Patient burden of Sjögren's: a comprehensive literature review revealing the range and heterogeneity of measures used in assessments of severity. RMD Open. 2017;3:e000443.

2. Ienopoli S, Carsons SE. Extraglandular manifestations of primary Sjogren's syndrome. Oral Maxillofac Surg Clin North Am. 2014;26:91-9.

3. Mariette X, Criswell LA. Primary Sjogren's syndrome. N Engl J Med. 2018;378:931-9.
4. Nocturne G, Mariette X. Sjogren syndrome-associated lymphomas: an update on pathogenesis and management. Br J Haematol. 2015;168:317-27.

5. Theander E, Henriksson G, Ljungberg O, Mandl T, Manthorpe R, Jacobsson LT. Lymphoma and other malignancies in primary Sjogren's syndrome: a cohort study on cancer incidence and lymphoma predictors. Ann Rheum Dis. 2006;65:796-803.

6. Zintzaras E, Voulgarelis M, Moutsopoulos HM. The risk of lymphoma development in autoimmune diseases: a meta-analysis. Arch Intern Med. 2005;165:2337-444.

7. Patel R, Shahane A. The epidemiology of Sjogren's syndrome. Clin Epidemiol. 2014;6:247-55.

8. Qin B, Wang J, Yang Z, Yang M, Ma N, Huang F, et al. Epidemiology of primary Sjogren's syndrome: a systematic review and meta-analysis. Ann Rheum Dis. 2015;74:1983-9.

9. Segal B, Bowman SJ, Fox PC, Vivino FB, Murukutla N, Brodscholl J, et al. Primary Sjogren's syndrome: health experiences and predictors of health quality among patients in the United States. Health Qual Life Outcomes. 2009;7:46.

10. Zhang Q, Wang X, Chen H, Shen B. Sjögren's syndrome is associated with negatively variable impacts on domains of health-related quality of life: evidence from Short Form 36 questionnaire and a meta-analysis. Patient Prefer Adherence. 2017;11:905-11.

11. Radstake T, van der Heijden E, Moret F, Hillen M, Lopes A, Rosenberg $\mathrm{T}$, et al. Clinical efficacy of leflunomide/hydroxychloroquine combination therapy in patients with primary Sjogren's syndrome: results of a placebo-controlled double-blind randomized clinical trial (Abstract L10). ACR 2018

12. Ferro F, Marcucci E, Orlandi M, Baldini C, Bartoloni-Bocci E. One year in review 2017: primary Sjogren's syndrome. Clin Exp Rheumatol. 2017;35: 179-91.

13. US Food and Drug Administration. Patient-reported outcome measures: use in medical product development to support labeling claims. https://www. fda.gov/media/77832/download. Accessed 22 June 2020

14. European Medicines Agency. Reflection paper on the regulatory guidance for the use of health-related quality of life (HRQL) measures in the evaluation of medicinal products. https://www.ema. europa.eu/en/documents/scientific-guideline/ reflection-paper-regulatory-guidance-usehealthrelated-quality-life-hrql-measuresevaluation_en.pdf. Accessed 22 June 2020. 
15. Patrick DL, Burke LB, Gwaltney CJ, Leidy NK, Martin ML, Molsen E, et al. Content validityestablishing and reporting the evidence in newly developed patient-reported outcomes (PRO) instruments for medical product evaluation: ISPOR PRO good research practices task force report: part 1-eliciting concepts for a new PRO instrument. Value Health. 2011;14:967-77.

16. US Food and Drug Administration. PDUFA V clinical outcomes assessment development and implementation: opportunities and challenges public workshop. https://www.fda.gov/media/92537/ download. Accessed 22 June 2020.

17. Lackner A, Ficjan A, Stradner MH, Hermann J, Unger J, Stamm T, et al. It's more than dryness and fatigue: the patient perspective on health-related quality of life in primary Sjögren's syndrome-a qualitative study. PLoS ONE. 2017;12:e0172056.

18. Synnot A, Hill S, Summers M, Taylor M. Comparing face-to-face and online qualitative research with people with multiple sclerosis. Qual Health Res. 2014;24:431-8.

19. Bowker N, Tuffin K. Using the online medium for discursive research about people with disabilities. Soc Sci Comput Rev. 2004;22:228-41.

20. Seror R, Ravaud P, Mariette X, Bootsma $H$, Theander E, Hansen A, et al. EULAR Sjögren's syndrome patient reported index (ESSPRI): development of a consensus patient index for primary Sjögren's syndrome. Ann Rheum Dis. 2011;70:968-72.

21. Seror R, Bowman SJ, Brito-Zeron P, Theander E, Bootsma H, Tzioufas A, et al. EULAR Sjogren's syndrome disease activity index (ESSDAI): a user guide. RMD Open. 2015;1:e000022.

22. Bowman SJ, Hamburger J, Richards A, Barry RJ, Rauz S. Patient-reported outcomes in primary Sjogren's syndrome: comparison of the long and short versions of the profile of fatigue and discomfort-sicca symptoms inventory. Rheumatology (Oxford). 2009;48:140-3.

23. FACIT.org. Questionnaires. https://www.facit.org/ facitorg/questionnaires. Accessed 10 Jan 2019.

24. Schreier M. Qualitative content analysis in practice. London: Sage Publishing; 2012.

25. Stamm TA, Bauernfeind B, Coenen M, Feierl E, Mathis M, Stucki G, et al. Concepts important to persons with systemic lupus erythematosus and their coverage by standard measures of disease activity and health status. Arthritis Rheum. 2007;57:1287-95.

26. Ramírez Sepúlveda JI, Kvarnström M, Brauner S, Baldini C, Wahren-Herlenius M. Difference in clinical presentation between women and men in incident primary Sjögren's syndrome. Biol Sex Differ. 2017;8:16. 